\title{
Empirical assessment of heat transmission and pressure loss in turbojet blades
}

\author{
Mahdi PourmohammadiRaad, AlirezaRoudbari \\ MSc of Mechanical Engineering, KNToosi University \\ Associate Professor of ShahidSattari University
}

\begin{abstract}
Barriers against the flow or jags can be used, increasing the heat transmission rate. Jags have many applications such as turbojet blade cooling, heat inverter and solar air heater. Geometry and arrangement of jags are effective on heat transmission and pressure loss. In present study, an empirical method has been utilized to study heat transmission and pressure loss in a square canal. The thin and square jags have been compared. The air considered between the $10^{3}$ to $3 * 10^{3}$ Reynolds. The step to jag height ratio equals to 20; the jag height than hydraulic diameter ratio equals to 0.068 and jags has been located at attack angle equal to $90^{\circ}$. Results show that heat transmission and pressure loss amount in thin jags is bigger than square jags. The amount of heat operation coefficient is bigger than square jags. The higher heat operation coefficient belongs to thin jags equal to 1.11 .
\end{abstract}

Keywords: jag, heat transmission improvement, turbojet, constant heat flux

\section{Introduction}

During the recent years, jags have obtained considerable applications in cases such as turbine cooling, solar heaters and heat inverters. The turbojet engines rely mainly on produced power via the output gases. In turbojet engines, the air enters into the compressor and compact but it is not useful for combustion because it has high velocity. Due to that the air sent to diffuse or velocity reducer. Then it sent to the combustion chamber.

A part of combustionpower used for turbine rotation and the rest, utilized for the production of buoyancy power. Cooling processes of the turbine segmentshas an important role because the input gas has high temperature. In this study the blade cooling is done, using the jags. Jags can separate the flow; therefore, it causes the pressure loss increasing in flow. Almost all developed turbine blades use this method for the blade cooling. The rate of convection heat transmission in canal is low for the air heating because the air has low heat conductivity coefficient and heat capacity (Gao et al. 2006). The low heat transmission depends on a sublayer adjacent the heat transmission surface, needs to break this sublayer. One method is the surface roughing (Aharwala et al, 2008).

Han et al. (1978) evaluated the jags form, attack angle and the step ratio to jags height on friction coefficient; in a rectangular canal with two rough walls, Figure 1 describes them. They found that the most heat transmission occur on relative step 10 and attack angle equals to $45^{\circ}$.

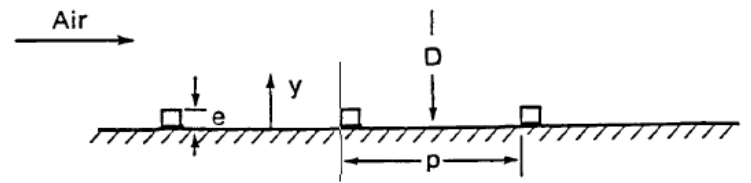

Fig1. Important geometric parameter of jags (Han et al, 1978)

Han et al. (1992) and Kiml et al. (2001) reported that attack angle of jags with $60^{\circ}$ has the better results than $45^{\circ}$.Lau et al. (1991) evaluated the heat transfer and pressure reduction in the completely expanded area in a square canal with discrete transverse jags. They found that heat transfer coefficient in discrete state is 10 to $15 \%$ more than continuous state.Cho et al, 2000, experimented the effect of attack angle and the number of discrete jags. They understood that the gap between the jags accelerate the flow and increase the heat transfer.Doherty et al, 2001, studied the effect of jags in a canal by the numerical and experimental methods. They found that when the canal dimension equals to 0.37 and the ratio of step than jags equals to 10 is the optimum state. Liou et al, 1993, studied the numerical and empirical methods of heat transfer in a canal with asymmetric jag locations. Also Ryu et al, 2007, evaluated the jag's form such as square, triangular and semicircular forms in heat transfer of turbulent flow in a wide range of Reynolds numbers. Billen et al, 2009, assessed the characteristics of heat transfer and friction for the turbulent and expanded airflow in a canal with circular, rectangular and trapezoidal furrows, empirically. 
Conclusions show the importance of jags in heat transfer mechanisms and devices such as solar heaters. However, the necessity of more studies in this field is obvious for quantitative and qualitative improvements. For this aim, an educational set for studying the jags effect has been designed in this article.

\section{Empirical device manufacturing}

Evaluating the step and height of jag in heat transfer, an empirical device has been designed and made. Figure 2 shows the general view of device.

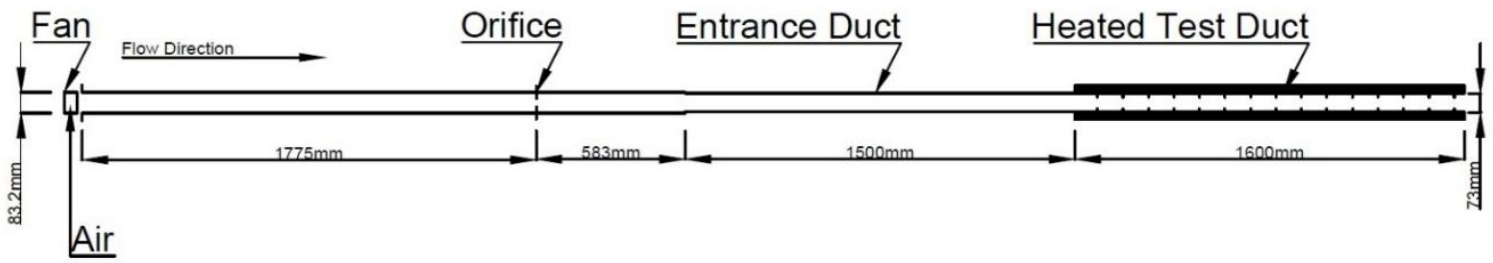

Fig2. Schematic of Empirical Device

A fan located at the beginning of device for the flow conduction into the canal. Its power is adjustable and the flux and Reynolds can be controlled. The orifice located then, the mass flux can be calculated by it. Figure 3 shows the fan.

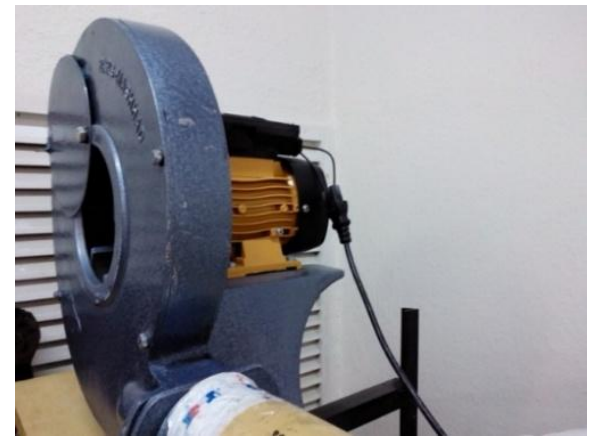

Fig3. A figure of used fan

Figure 4 shows the orifice. A punched surface located against the flow direction; it causes the pressure loss. A liquid manometer used to measure this loss.

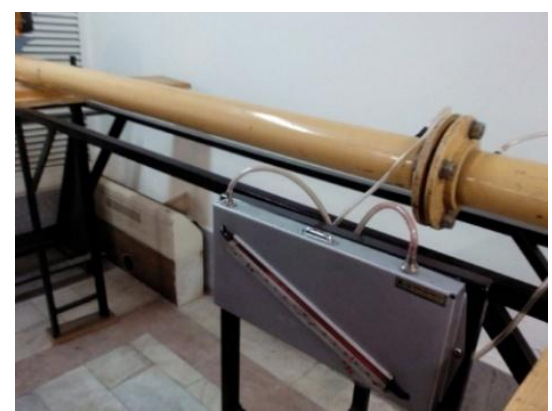

Fig4. The Orifice

Figure 5 shows that after the orifice a glass canal, $76 * 76 \mathrm{~mm}$ cross section with $1524 \mathrm{~mm}$ length, located to generate a completely expanded flow. 


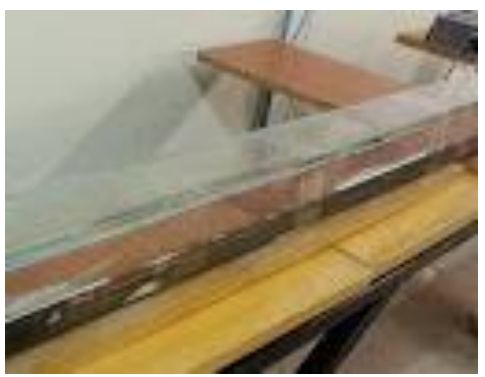

Fig5. A view of glass canal

Heating area located after the glass canal. This area is a steel canal with $76 * 76 \mathrm{~mm}$ cross section, 1600 $\mathrm{mm}$ length and $3 \mathrm{~mm}$ thickness. Electrical heaters with plate form utilized for the heating process with specific resistance and providing the $1000 \mathrm{~W}$ power. An important property of this heater is the continuous heat flux. Thermistors used, measuring the temperature at various points. Figure 6 shows the thermistors locating way into the canal.

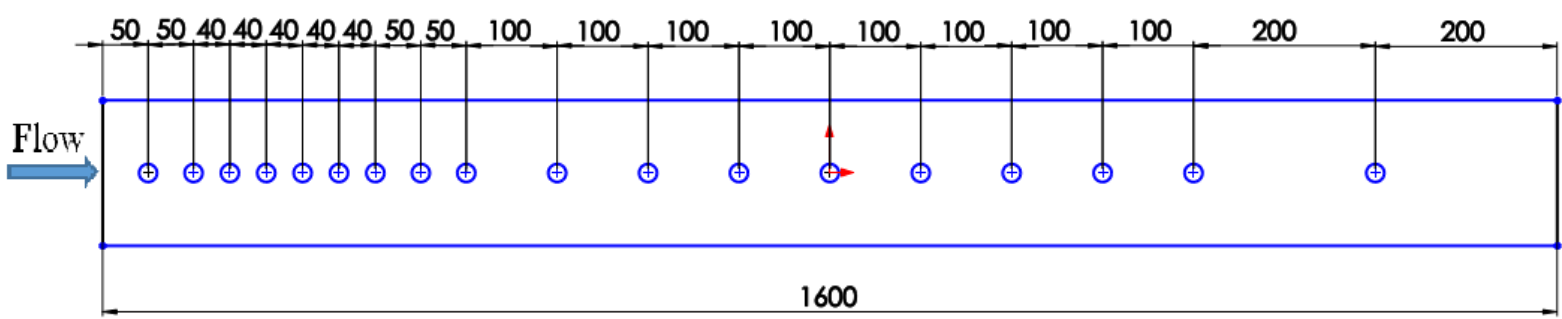

Fig6. Thermistors locating way into the canal

Wooden jags with $0.3 \mathrm{~mm}$ thickness utilized, fluctuating the flow (figure 7).

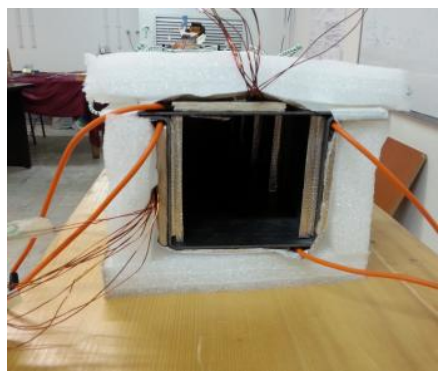

Fig7. A view of used jags in canal

Ratio of P/e equals to 20. e/D ratio equals to 0.068 . The jags located in $90^{\circ}$ attack angle in two opposite surfaces.

\section{Governing Equations}

Reynolds number calculated as below:

Where the $\mathrm{u}$ is the air velocity, $\rho$ is the Density equals to $1.177, \mathrm{D}_{\mathrm{h}}$ is the equivalent hydraulic diameter and $\mu$ is the dynamic viscosity equals to $1.864 \times 10-5$. The heat transfer coefficient obtained as below: 
Where the $\mathrm{q}$ is the heat flux and $\mathrm{q}_{\text {loss }}$ is the loss flux that considered 5 to $20 \%$ of heat flux. The loss flux in this study considered $5 \%$ because of suitable insulation. $\mathrm{Tw}$ and $\mathrm{Tb}$ are the temperature of wall and canal center respectively. Nusselt number $(\mathrm{Nu})$ obtained as below:

Where $\mathrm{k}$ is, the air heat conductivity equals to 0.0245 . Average Nu calculated as below:

Relation 5 shows the friction coefficient equation.

Where $\mathrm{L}$ is the length of part that pressure loss measured along it. The coefficient of thermal performance calculated as below:

The $\mathrm{Nu}$ and $\mathrm{f}$ compared with relations 7 (Kakac and Spalding, 1979) and eight (Han et al, 1984) for validation assessment.

$N u_{D}=0.023 \operatorname{Re}_{D}{ }^{0.8} \operatorname{Pr}^{0.4}$

The amount of 2Rav/D considered equal to 1.156

\section{Results}

In this part, for the comparison and validation, results of without jag surface measurements compared with obtained results of relations 7 and 8 for different Reynolds. As it can be seen in figures 8 and 9, there is suitable compatibility between the experiment results and the relations 7 and 8 .

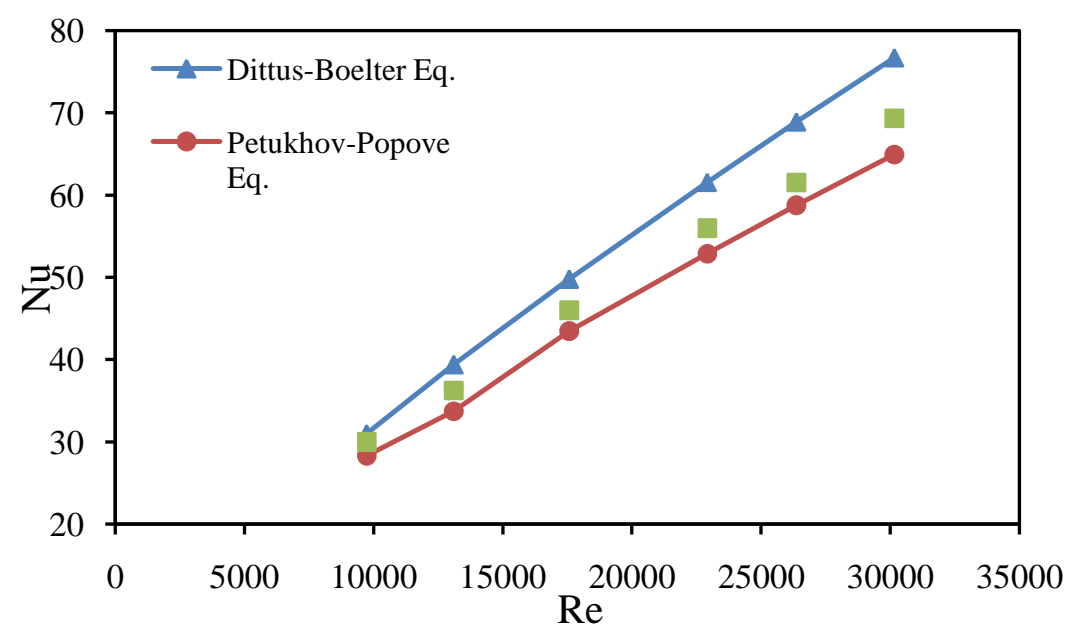

Fig8. Nu graph of flat surface in compare to Petokhov-Popov and Dittos- Bolter relation 


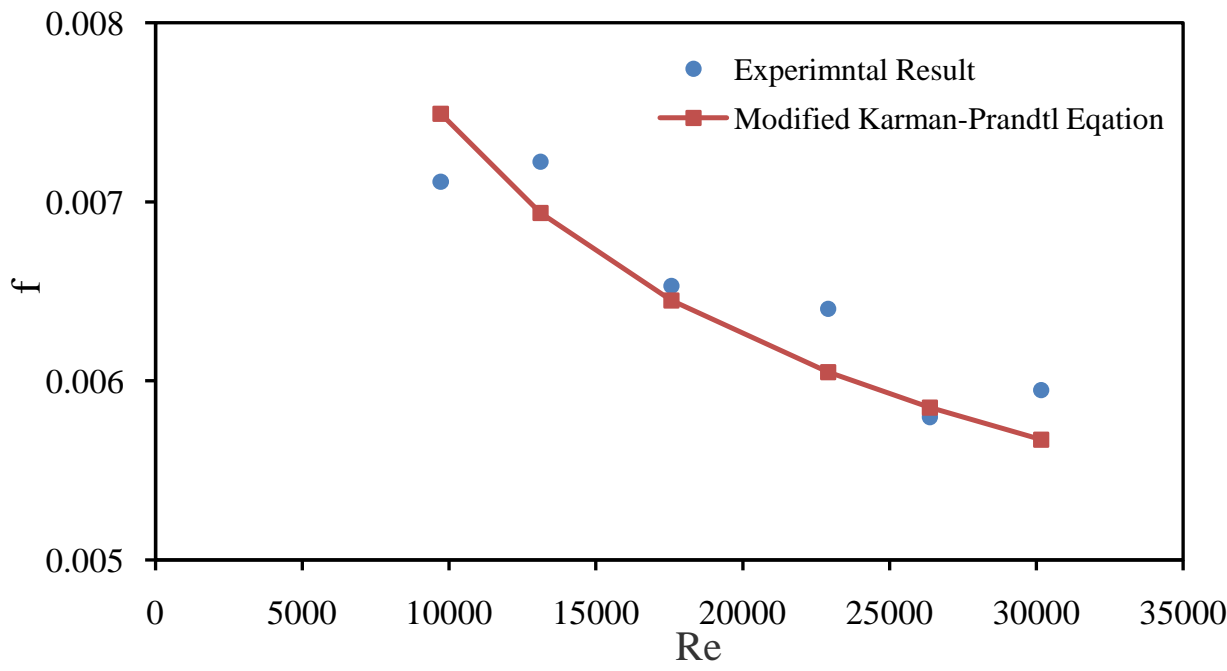

Fig9. Friction coefficient graph of flat surface in laboratory, comparing with Karman- Prantel relation

Obtained results for the flow development

The results of Nu number in different ratio of X/D have been shown in figure 10 for different Reynolds.

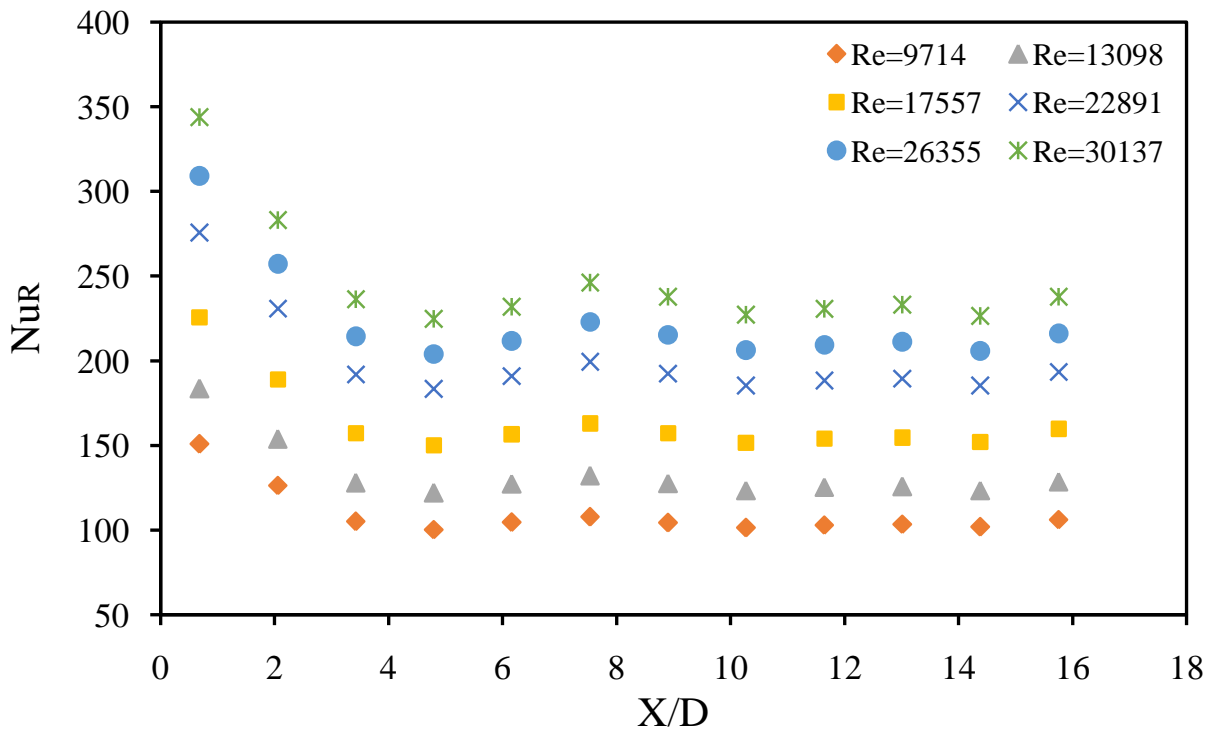

Fig10. Thermal improvement of rough bed in different Reynolds for $\mathrm{P} / \mathrm{e}=\mathbf{2 0}, \mathrm{e} / \mathrm{D}=\mathbf{0 . 0 6 8}$ and $\theta=90$

It can be seen obviously that flow improved at the fourth jag. Even at the developed area, the $\mathrm{Nu}$ number has the fluctuation because of the jag presence. The separation occurs because of the jag's presence. Therefore, the Nu reduces before the jags.

\section{The thin and square jag comparison}

The thin jags and square ones comparison, the results have been assessed in similar state with Han results (Han et al, 1984). The P/e and e/D have been considered equal to 20 and 0.068 respectively with the attack angle equal $90^{\circ}$. Figure 11 shows the $\mathrm{Nu}$ graph base on Reynolds for thin and square jags. In all Reynolds, the heat transmission in thin jags are bigger than square ones. Because the thin jags stopped the thermal boundary layer distribution. They increase the agitation than the square ones. The most $\mathrm{Nu}$ increasing than the flat canal in thin jags are 173-197\% and in square jags are 99-108. 


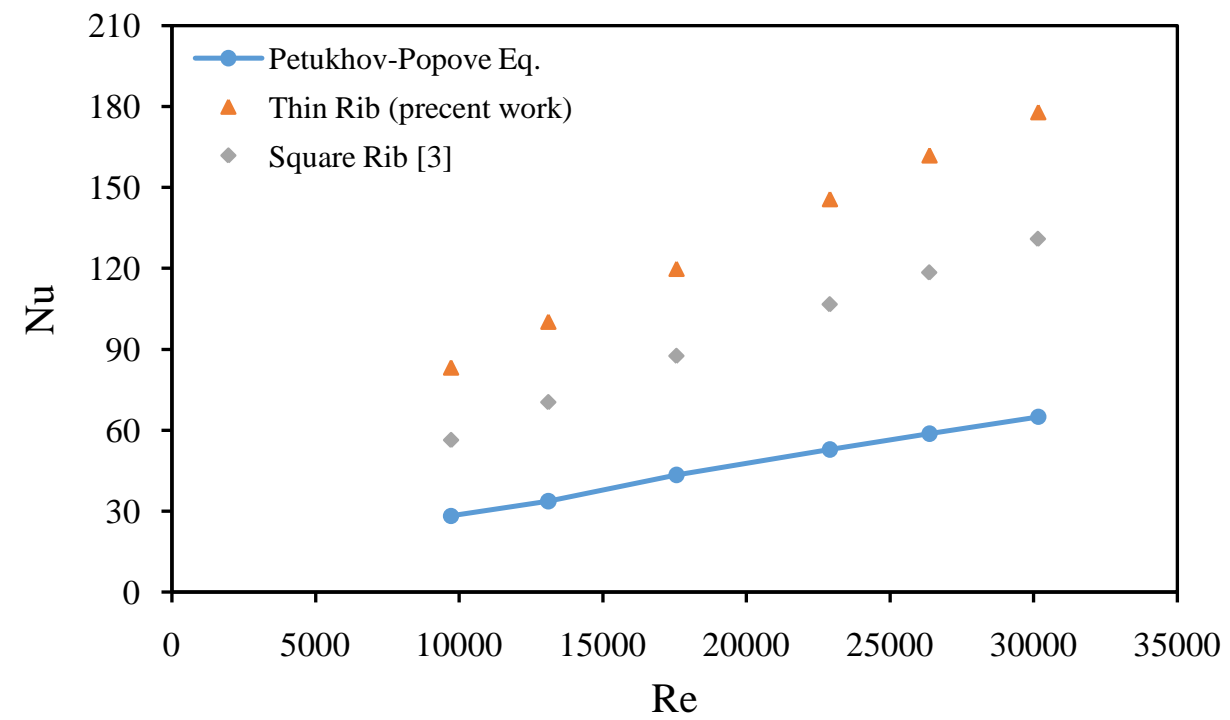

Fig11. The Nu number comparison in thin jags with square ones $(\mathrm{P} / \mathrm{e}=\mathbf{2 0}, \mathrm{e} / \mathrm{D}=\mathbf{0 . 0 6 8}$ and $\theta=90)$

Figure 12 shows the pressure loss because of the jag utilization in both thin and square states in different Reynolds. The result comparison with Han results show that thin jags caused more pressure loss than square ones. The pressure loss for square jags equals to $4.82-6.02$ for flat canal and is 8-10.94 for thin jags.

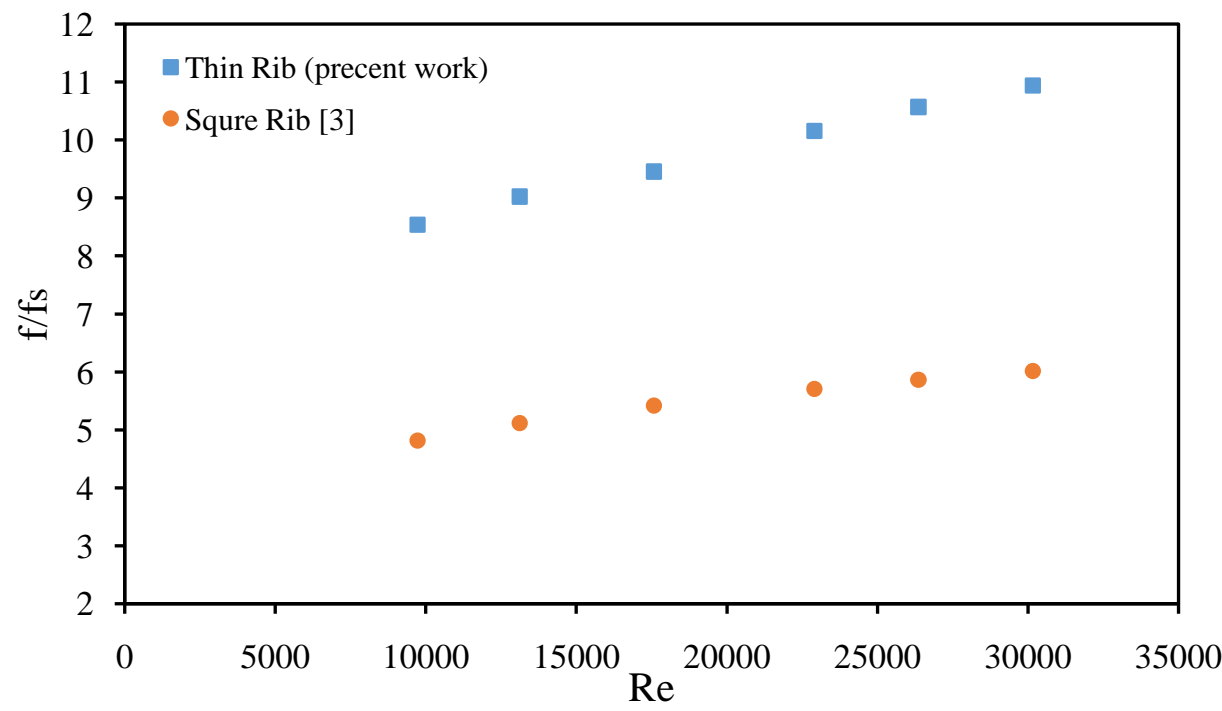

Fig12. The friction coefficient comparison of thin jags with square ones in $\mathrm{P} / \mathrm{e}=\mathbf{2 0}, \mathrm{e} / \mathrm{D}=\mathbf{0 . 0 6 8}$ and $\theta=$ 90

Figure 13 shows the thermal operation coefficient in different Reynolds for both thin and square states. Considering the graphs, it can be concluded that thin jags have the better operation than the square state. 


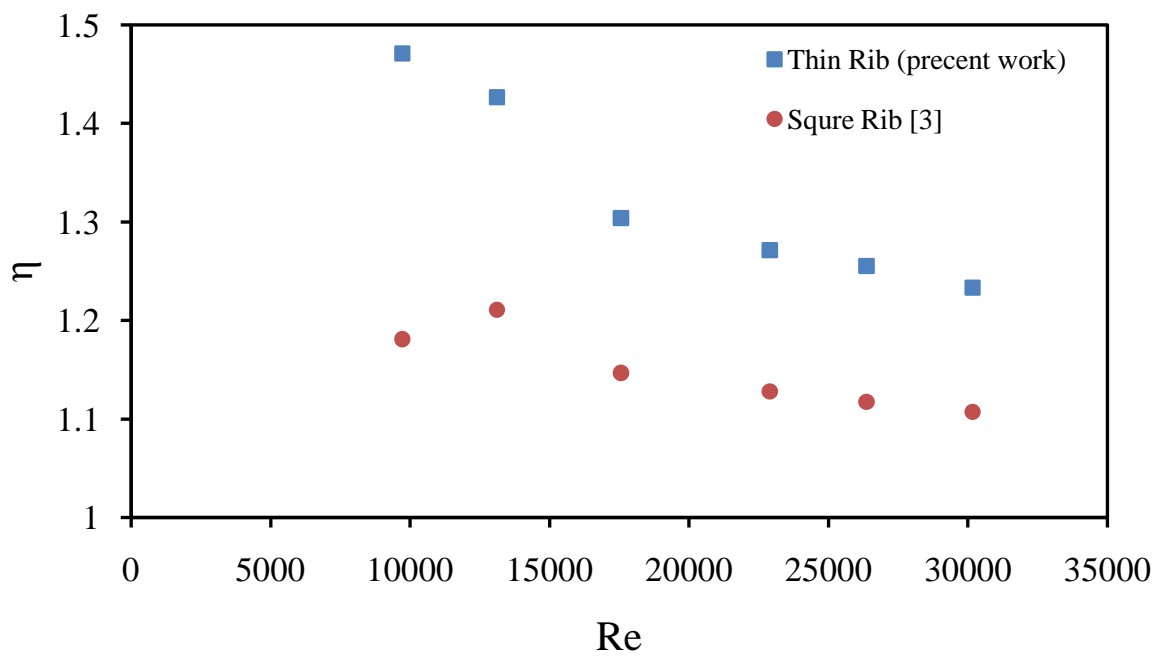

Fig13. Comparison of thermal operation coefficient between the thin and square jags in $P / e=20$, $\mathrm{e} / \mathrm{D}=\mathbf{0 . 0 6 8}$ and $\boldsymbol{\theta}=\mathbf{9 0}$

\section{Conclusion}

This study focused on experimental setting manufacturing for the heat transmission and pressure loss assessment in thermal exchanger canals, with turbine blade cooling in turbojets using the thin jags. At first, the four side flat canal assessed for the turbojet blade simulation and showed the suitable correlation. For X/D equals to five relates to fourth jag, results show the developed flow and increases along the Reynolds increasing. Heat transmission increasing and pressure loss of thin jags is more than the square jags. Finally, it was obtained that thermal operation coefficient for thin jags is more than square ones. The most thermal operation coefficient in turbojets turbine blades for thin jags obtained equal to 1.48 in Reynolds 10000.

\section{References}

[1]. Gao A., Wenxian Lin A. B., Tao Liu a., Chaofeng Xia., 2006. "Analytical and experimental studies on the thermal performance of cross-corrugated and flat-plate solar air heaters", Applied Energy, Vol. 84, pp. 425-441.

[2]. K. R. Aharwala., B. K. Gandhib., J. S. Sainib., 2008. "Experimental investigation on heat-transfer enhancement due to a gap in an inclined continuous rib arrangement in a rectangular duct of solar air heater", Renewable Energy, Vol. 33, pp. 585-596.

[3]. Han J. C., Glicksman L. R., Rosenow W. M., 1978. "Investigation of heat transfer and friction for rib-roughened surfaces". Int J Heat Mass Transfer, Vol. 21, pp. 1143-56.

[4]. J. C. Han., J. S. Park., C. K. Lei., 1985. "Heat Transfer Enhancement in Channels with Turbulence Promoters", ASME J. Eng. Gas Turb, Vol. 107, pp. 628-635.

[5]. Han J. C., Park J. S., 1988. "Developing heat transfer in rectangular channels with rib turbulators". Int J Heat Mass Transfer, Vol. 3, pp. 183-95.

[6]. Han J. C., Zhang Y. M., 1992. High performance heat transfers ducts with parallel broken and V- shaped broken ribs". Int J Heat Mass Transfer, Vol. 35, pp. 513-23.

[7]. Kiml R, Mochizuki S, Murata A, 2001. "Effects of rib arrangements on heat transfer and flow behavior in a rectangular rib roughened passage". J Heat Transfer, Vol. 123, pp. 675-81.

[8]. Lau S. C., McMillin R. D., Han J. C., 1991. "Turbulent heat transfer and friction in a square channel with discrete rib turbulators". Trans ASME, J Turbo Machinery, Vol. 113, pp. 360-6.

[9]. Lau S. C., McMillin R. D., Han J. C., 1991. "Heat transfer characteristics of turbulent flow in a square channel with angled rib". Trans ASME, J Turbomachinery, Vol. 113, pp. 367-74.

[10]. Cho H. H., Wu S. J., Kwon H. J., 2000. "Local heat/mass transfer measurement in a rectangular duct with discrete ribs". J Turbomachinery, Vol. 122, pp. 579-86.

[11]. O’Doherty T., Jolly A. J., Bates C. J., 2001. "Optimisation of heat transfer enhancement devices in a bayonet tube heat exchanger". Appl Therm Eng, Vol. 21, pp. 19-36.

[12]. Liou T. M., Hwang J. J., Chen S. H., 1993. "Simulation and measurement of enhanced turbulent heat transfer in a channel with periodic ribs on one principal wall". Int J Heat Mass Transfer, Vol. 36, pp. 507-17.

[13]. Ryu D. N., Choi D. H., Patel V. C., 2007. "Analysis of turbulent flow in channels roughened by two-dimensional ribs and threedimensional blocks". Part I: Resistance. Int J Heat Fluid Fl, Vol. 28, pp. 1098-111.

[14]. Ryu D. N., Choi D. H., Patel V. C., 2007. "Analysis of turbulent flow in channels roughened by two-dimensional ribs and threedimensional blocks". Part II: Heat transfer. Int J Heat Fluid Fl, Vol.28, pp. 1112-24.

[15]. Bilen K., Cetin M., Gul H., Balta T., 2009. "The investigation of groove geometry effect on heat transfer for internally grooved tubes", Appl. Therm. Eng, Vol. 29, pp. 753-761.

[16]. P. W. Dittus and L. M. K. Boelter., 1985. "Heat transfer in automobile radiators of the turbular type", Univ. Calif. Publ. Eng., Vol.2, No. 13, Oct. 17, 1930, pp 443-461; reprinted in Int. Cmmun. Heat Mass Transfer, Vol. 12, pp. 3-22.

[17]. S. Kakac, and D. Spalding, 1979. "Turbulent Forced Convection in Channels and Bundles", New York: Hemisphere Publishing Corp.

[18]. j. c. Han, J. S. Park and C. K. Lei, November 1984. "Heat Transfer and Pressure Drop in Blade Cooling Channels With Turbulence Promoters", NASA. 